\title{
Odnos med ustvarjalnostjo in igralnim materialom v kontekstu simbolne igre ${ }^{\#}$
}

\author{
Jelka Fric Jekovec ${ }^{*}$ in Valentin Bucik ${ }^{2}$ \\ ${ }^{1}$ Ljubljana \\ ${ }^{2}$ Oddelek za psihologijo, Filozofska fakulteta, Univerza v Ljubljani
}

Povzetek: Ker se v simbolni igri odvijajo številni razvojni procesi na spoznavnem, čustvenem in socialnem področju, naj bi bila prav simbolna igra prostor, kjer otrok razvija svoje potenciale, med drugim tudi ustvarjalnost. Namen raziskave je bil proučiti odnos med ustvarjalnostjo otroka $\mathrm{v}$ zgodnjem otroštvu in različnimi vrstami igralnega materiala $\mathrm{z}$ vidika simbolne igre. 59 otrok, starih med pet in šest let, je pred pričetkom in po končani deseti igralni seansi izpolnilo Preizkus ustvarjalnega mišljenja TCT-DP. Med igralnimi seansami se je vsak otrok samostojno igral z eno od šestih vrst igrač, ki so se med seboj razlikovale v treh dimenzijah: strukturiranosti, realističnosti in kompleksnosti. Pričakovali smo, da se bo mera ustvarjalnosti zvišala pri vseh otrocih, vendar različno glede na vrsto igralnega materiala, s katerim so se otroci igrali. Rezultati so pokazali, da razlike $v$ meri ustvarjalnosti med obema merjenjema niso bile statistično pomembne, zato ne moremo sklepati, da je različen igralni material pomembno prispeval k razliki v meri ustvarjalnosti, pokazal pa se je majhen porast mere ustvarjalnosti pri skupini otrok, ki je imela $\mathrm{v}$ igralnih seansah na voljo nizko strukturiran, nizko realističen in nizko kompleksen igralni material, kar je podobno, kot kažejo izsledki nekaterih drugih, primerljivih raziskav.

Ključne besede: ustvarjalnost, igra, igralni material, igrače, zgodnje otroštvo

\section{The relationship between creativity and variety of play material in the context of symbolic play}

\author{
Jelka Fric Jekovec $^{1^{*}}$ and Valentin Bucik ${ }^{2}$ \\ ${ }^{1}$ Ljubljana, Slovenia \\ ${ }^{2}$ Department of Psychology, Faculty of Arts, University of Ljubljana, Slovenia
}

\begin{abstract}
During children's symbolic play many cognitive, emotional and social processes take place. A child develops her potential through symbolic play, and creativity is one such potential. Our research focused on investigating the relationship between creativity in early childhood and physical representation of play material in the context of symbolic play. 59 children were included in the study, aged from five to six years. We assessed their creativity before and after ten play-sessions using the Test for Creative Thinking TCT-DP. Each child played individually with one of six types of play material that varied with respect to three characteristics: structure, realism, and complexity. We hypothesized that creativity would increase for all types of play material but that it would not increase evenly across play materials. Due to statistically insignificant differences in creativity measures over time, we could not validate these hypotheses. We did however find a small increase in creativity for a group that played with low-structured, low-realism and low-complexity play material. This result is consistent with other similar research in the field.
\end{abstract}

Keywords: creativity, play, play material, toys, early childhood

\footnotetext{
"Naslov/Address: Jelka Fric Jekovec, Ljubljana, Reška ulica 7, 1000 Ljubljana, e-pošta: jelka.fritz@gmail.com

\#Članek je nastal v okviru doktorskega študija, ki ga je delno sofinancirala Evropska unija, in sicer iz Evropskega socialnega sklada. Sofinanciranje se izvaja v okviru Operativnega programa razvoja človeških virov za obdobje 2007-2013, 1. razvojne prioritete Spodbujanje podjetništva in prilagodljivosti; prednostne usmeritve 1.3: Štipendijske sheme.

Članek je licenciran pod pogoji Creative Commons Attribution 4.0 International licence. (CC-BY licenca). The article is licensed under a Creative Commons Attribution 4.0 International License (CC-BY license).
} 


\section{Ustvarjalnost otrok in simbolna igra $v$ zgodnjem otroštvu}

Sodobne biopsihološkosociološke teorije ustvarjalnost razlagajo kot celovito interakcijo med biološkimi, psihološkimi in sociološkimi dejavniki (Dacey, 2011; Russ in Fiorelli, 2010). Ustvarjalnost lahko opredelimo kot produkcijo novih, presenetljivih, relevantnih, uporabnih, učinkovitih miselnih ali fizičnih konstruktov (Dudek, 1974; Kaufman in Sternberg, 2010; Russ, 2011). Nekateri avtorji (npr. Dudek, 1974; Russ in Fiorelli, 2010) se sprašujejo, ali so lahko otroci sploh ustvarjalni, saj njihovi produkti redko dosegajo omenjene kriterije. S.W. Russ (2011) pravi, da so otroci ustvarjalni, kadar so njihovi izdelki ali ideje novi in uporabni za njih same. Ustvarjalni produkti otrok lahko opazovalca presenetijo oziroma mu prek te izkušnje omogočijo nov uvid v stvarnost sveta. Vygotsky pravi (1967/2004), da je elemente ustvarjalnega procesa mogoče prepoznati tudi v igri otroka $\mathrm{v}$ zgodnjem otroštvu, saj predvsem igra vlog ni le reprodukcija že doživetega, pač pa je ustvarjanje nove realnosti na podlagi doživetih vtisov.

Splošne teorije razvoja ustvarjalnosti, ki bi bila podprta z empiričnimi podatki, ni (Arnold, Subotnik in Ross, 2011; Russ in Fiorelli, 2010). Vygotsky (1967/2004) meni, da se domišljija, ki je temelj ustvarjalnega dejanja, razvija počasi in ima na vsaki stopnji značilen izraz. Pravi, da je domišljija odvisna od količine in mnogoterosti izkušenj posameznika, od razvitosti oziroma celovitosti posameznikovega odnosa do okolja ter od raznolikosti in stabilnosti interesov, zato so odrasli bolj ustvarjalni od otrok. Vendar Vygotsky meni, da ni naključje, da domišljija izredno poraste v zgodnjem otroštvu. Ustvarjalno dejanje pojmuje kot produkcijo novega fizičnega ali mentalnega konstrukta, pri katerem posameznik z domišljijo ali kombinatorno funkcijo možganov iz obstoječih, poznanih, elementarnih delov izkušnje oblikuje nove konstrukte, še nedoživete kombinacije. Ta proces je zavestna dejavnost in njen pojav je posledica odmika od primeža konkretnega, predmetnega sveta. Otrok v zgodnjem otroštvu že uporablja miselne predstave in simbolne reprezentacije, ki so ključnega pomena za pojav ustvarjalnosti (Russ in Fiorelli, 2010). Runco (2007) se nasloni na teorije Piageta, Freuda in Vygotskega, ko razlaga razvoj ustvarjalnosti oziroma spoznavne in čustvene procese, ki so tesno povezani z ustvarjalnostjo in simbolno igro (Russ, 2011).

Runco (2007) ustvarjalnost opiše kot »... adaptacijo, ki jo sproži neravnovesje med pričakovanim in obstoječim, pri čemer so spoznavne transformacije, ki vodijo do ustvarjalnih idej, posledica asimilacije, trenutkov nenadnega vpogleda ali »aha učinkov« in akomodacije« (str. 44). Neravnovesje med pričakovanim in obstoječim ter miselna adaptacija sta značilna tudi za otrokovo igro, zlasti od zgodnjega otroštva naprej, ko otrok prek asimilacije stvarnost prilagaja potrebam ega, prek akomodacije pa prilagaja spoznavne sheme stvarnosti (Piaget, 1962). Runco(2011) meni, da se procesa asimilacije in akomodacije skozi različne stopnje razvoja ne spreminjata bistveno, spreminja se pa vrsta informacij, ki jo je posameznik sposoben asimilirati in akomodirati, kar je posledica razvijajočih se spoznavnih shem, skozi katere posameznik interpretira neko izkušnjo. Na predoperativni stopnji razvoja so otroci sposobni spontanega simbolnega mišljenja z informacijami, ki so vezane na »tukaj in zdaj«, a za načrtno, konceptualno ustvarjalno mišljenje, kot ga zmorejo odrasli, so potrebne tudi druge sposobnosti, ki se razvijejo na višjih razvojnih stopnjah. Tako za ustvarjalnost kot tudi za igro sta pomembna divergentno mišljenje in sposobnost transformacije. Divergentno mišljenje omogoča proste asociacije, tekočnost, izvirnost, prožnost idej (Guilford, 1967a), sposobnost transformacije, opuščanje starih vzorcev mišljenja in oblikovanje novih spoznavnih shem iz novih informacij (Russ, 2004). So pa simbolni igri in ustvarjalnosti skupni tudi drugi spoznavni procesi: iskanje in reševanje problemov (Csikszentmihalyi, 1990), preklapljanje med logičnim in narativnim slogom mišljenja (Singer in Singer, 1990), predmetna reprezentacija (Russ, 2011), iskanje alternativnih pristopov $\mathrm{k}$ reševanju problemov (Weisberg, 1988), sposobnost vpogleda (Sternberg, 1988) in teorija uma (Marjanovič Umek in Fekonja Peklaj, 2008).

$\mathrm{Na}$ vlogo čustvenih procesov pri razumevanju razvoja ustvarjalnosti je prvi opozoril Freud s konceptom primarnegaprocesnegamišljenja(Russ, 2011), kijeznačilna oblika mišljenja v otroštvu in sanjah ter teži k takojšni zadovoljitvi potreb (Suler, 1980). Spoznavno-čustvena narava primarnega procesnega mišljenje naj bi spodbujala divergentno mišljenje, in sicer tekočnost, prožnost mišljenja in tok asociacij, sposobnost transformacije, spoznavno integracijo materiala s čustvenim nabojem ter dostop do misli in podob $\mathrm{s}$ čustvenim nabojem (Russ, 2001). Vygotsky (1967/2004) pa je opozoril na dvosmerno povezavo med čustvi in domišljijo. Pravi, da vsak vtis izzove čustven odziv in tudi vsako čustvo išče ustrezno podobo, ki ustreza specifičnemu razpoloženju $\mathrm{v}$ določenemu trenutku. Čustveni odzivi postanejo "gravitacijski centri podob«, ki poleg čustvene nimajo druge povezave. Čustva imajo prikrit vpliv na povezovanje neobičajnih združevanj vtisov. Sodobnejša raziskovanja povezav med ustvarjalnostjo in igro razkrivajo tudi velik pomen čustvenih procesov v temu odnosu (Russ, 2011), in sicer: »... odprtost do doživljanja čustev (pozitivnih in negativnih), dostop do idej in podob, ki nosijo čustven naboj, doživljanje zadovoljstva ob izzivih in reševanju problemov, spoznavna integracija čustev (umestitev čustev v spoznavni kontekst), regulacija in modulacija čustev (sposobnost hkratnega doživljanja in nadziranja čustvenega stanja)« (Russ, 2004, str. 4).

Runco (2006) se pri razlagi razvojnih trendov ustvarjalnosti nasloni na Kohlbergovo teorijo moralnega razvoja, ko skuša pojasniti (navidezni) upad izvirnega mišljenja okoli otrokovega desetega leta starosti. V zgodnjem otroštvu je otrok na predkonvencionalni stopnji moralnega razvoja. Ker je njegovo moralno presojanje bolj egocentrično in hedonistično kot presojanje otroka na konvencionalni stopnji, so mlajši otroci manj občutljivi 
za konvencije, norme in pritisk vrstnikov kot starejši vrstniki (Marjanovič Umek in Zupančič, 2009). Runco (2006) navaja, da občutljivost za konvencije, norme in pritisk vrstnikov učinkuje na tok asociacij in divergentno mišljenje, kar povzroči upad izmerjene ustvarjalnosti otrok okoli desetega leta. $\mathrm{Na}$ konvencionalni stopnji razvoja otroci bolj inhibirajo nekonvencionalna vedenja in ideje, zato so pogosto bolj dobesedni pri izražanju, njihovi izdelki pa so bolj realistični. Na podobne ugotovitve opozarjajo tudi izsledki drugih študij (Smith in Carlsson, 1983; Torrance, 1968).

Tudi izsledki več empiričnih raziskav so potrdili povezanost igre z razvojem ustvarjalnosti. Fisher (1992; v Russ, 2011) je opravil meta-analizo 46 raziskav o učinkih igre na spoznavni, govorni, čustveni ter socialni razvoj in ugotovil, da sociodramska oziroma simbolna igra spodbuja razvoj na vseh proučevanih področjih, najmočnejšo povezavo pa je našel med igro in divergentnim mišljenjem ter sposobnostjo menjavanja perspektive. A. S. Lillard in sodelavci (2013) so bili kritični do Fisherja zaradi uporabe neustreznih statističnih postopkov. A. S. Lillard in sodelavci so proučevali odnos med igro pretvarjanja in razvojnimi izidi otrok na več področjih. Pri preučevanju učinka igre na ustvarjalnost so primerjali ugotovitve enajstih eksperimentalnih in sedmih korelacijskih raziskav. Čeprav so izsledki štirih eksperimentalnih raziskav, ki so proučevale kratkoročni vpliv igre pretvarjanja, ter rezultati treh od sedmih korelacijskih raziskav, ki so proučevale dolgoročni učinek igralne intervencije na ustvarjalnost, dosledno kazali na pozitivni učinek, so A.S. Lillard in sodelavci podvomili, da obstaja vzročno posledični odnos med igro in ustvarjalnostjo. Opozorili so na nekatere metodološke pomanjkljivosti proučevanih raziskav, kot sta npr. odsotnost kontrolne skupine in morebitna pristranskost testatorjev. Zaradi nedoslednih izsledkov korelacijskih raziskav so predpostavili, da obstaja med igro otrok in njihovo ustvarjalnostjo mediacijska spremenljivka. Kot najbolj verjetno so izpostavili prav značilnost igralnega materiala.

\section{Značilnost igralnega materiala in simbolna igra otrok}

Wachs (1985) je opozoril na vlogo ne le socialnega, pač pa tudi fizičnega okolja na razvoj otroka. Fizično okolje je skupek zaznavnih dražljajev, ki so povezani z značilnostmi predmetov, in ustvarja kontekst za sociale interakcije. Igralni material je del otrokovega fizičnega okolja, za katerega Lewin (1931) pravi, da ni nevtralno. Značilnosti igralnega materiala so povezane $\mathrm{z}$ otrokovo interpretacijo predmetne funkcije (Robinson in Jackson, 1987) oziroma Z vsebino in obliko otroške igre (Marjanovič, 1981).

Robinson in Jackson (1987) sta povzela številne izraze, s katerimi so avtorji opisovali značilnosti igralnega materiala: strukturiranost, realističnost, kompleksnost, podrobnost, izdelanost in podobnost »resničnim predmetom«. V pričujoči raziskavi smo značilnosti igrač opisali s tremi dimenzijami: strukturiranost, realističnost in kompleksnost. Strukturiranost smo opredelili kot stopnjo določenosti fizičnih značilnosti igralnega materiala. Značilnosti nizko strukturiranega igralnega materiala je možno spreminjati (npr. modelirna masa ima lahko različno fizično podobo), visoko strukturiranega pa ne (npr. lastnosti seta za igranje zdravnika so določene s strani oblikovalca igrače in jih ni mogoče spreminjati). Z dimenzijo realističnosti smo opisali stopnjo podobnosti med igračo in predmetom, ki ga predstavlja (Marjanovič Umek in Lešnik Musek, 1998). Predmet je nizko realističen, če v realnosti nima ustreznega »dvojnika«, ali visoko realističen, če je glede na svoje značilnosti (velikost, razmerje posameznih delov, barva, vzorec, tekstura ali oblika) verodostojna replika predmeta (npr. mini čajni servis). Raven podrobnosti opisujemo ločeno z dimenzijo kompleksnosti, s katero opišemo, koliko fizičnih značilnosti oziroma koliko funkcionalnih zmogljivosti ima igrača. Visoko kompleksna igrača ima veliko značilnosti (npr. mini kuhinja ima delujoča vratca pečice, vrtljive gumbe, označene grelne plošče štedilnika), nizko kompleksna pa malo (punčka iz cunj ima zgolj stilizirano obliko glave in obleke brez podrobnosti oči, ust in okončin).

Izsledki raziskav kažejo, da otroci v zgodnjem otroštvu pri igri z manj izdelanim (torej nizko strukturiranim, realističnim in kompleksnim) igralnim materialom izvedejo več predmetnih zamenjav (Einsiedler, 1986; McLoyd, 1983), uporabijo več raznolikih tem (McGhee, Ethridge in Benz, 1984; Nakamine, 1979), v večji meri raziskujejo material (McGhee in sod., 1984), uporabljajo več konstrukcijske igre (Nakamine, 1979) in več govornega izražanja (Olszewski in Fuson, 1982) kot otroci, ki imajo na voljo bolj izdelan igralni material. Slednji prikažejo več posnemanja (Einsiedler, 1986; Treinies, Einsiedler in Bosch 1988), več metakomunikacije (Treinies in sod., 1988), več simbolne igre (Nakamine, 1979) in več igre pretvarjanja (McGhee in sod., 1984). Z visoko izdelanimi vsakdanjimi predmeti otroci $v$ igri ne zmorejo izvajati predmetnih zamenjav (Oncu in Unluer, 2010). Nekateri avtorji pa so ugotovili, da izdelanost igrače ni povezana s količino igre vlog (Einsiedler, 1986; McLoyd, 1983; Treinies in sod., 1988), domišljijske igre (Marjanovič Umek in Lešnik Musek, 1998; Olszewski in Fuson, 1982), izražene domišljije (Pulaski, 1970), z elaboriranostjo igre (Robinson in Jackson, 1987) ali pogostostjo predmetnih zamenjav (Treinies in sod., 1988). Glede priljubljenosti igrač ugotovitve niso dosledne. Einsiedler (1986) je poročal o manjšem interesu za igro z bolj izdelanim materialom, Robinson in Jackson (1987) pa o večjem.

Igralni material, ki je bil uporabljen $\mathrm{v}$ različnih raziskavah, je zelo variiral $\mathrm{v}$ vseh treh dimenzijah (v strukturiranosti, realističnosti in kompleksnosti), kar bi lahko bil en od razlogov za nedosledne ugotovitve. A kljub temu se kaže trend, da manj izdelane igrače omogočajo več predmetnih zamenjav oziroma manj posnemanj in spodbujajo bolj raznolike igralne teme, kar bi lahko imelo pozitivni učinek na ustvarjalnost otrok. Pogostejše 
predmetne zamenjave $\mathrm{v}$ igri bi lahko spodbujale razvoj sposobnosti transformacije, ki je eden od značilnih spoznavnih procesov ustvarjalnosti. Tudi raznolike, zlasti domišljijske igralne situacije bi lahko otroku nudile okolje novih izkušenj, kjer pridobiva nove kombinatorne elemente domišljije in jih sestavlja $\mathrm{v}$ še nepreizkušene kombinacije. Raznolikost igralnih situacij bi bila lahko povezana tudi s pogostejšo menjavo perspektive.

$\mathrm{V}$ naši raziskavi smo na vzorcu otrok, starih med pet in šest let, proučevali odnos med igralnim materialom in mero ustvarjalnosti v kontekstu simbolne igre. Otroci so se igrali z različnim materialom, ki se je razlikoval glede na strukturiranost, realističnost in kompleksnost oziroma po vrsti igrač (lutke, lego kocke, pametna naprava, polizdelki, replike). Preverjali smo veljavnost dveh hipotez. Prva hipoteza je bila, da bo mera ustvarjalnosti otrok po desetih igralnih seansah narasla. Druga hipoteza je bila, da bo mera ustvarjalnosti narasla različno, in sicer glede na vrsto igralnega materiala, s katerim se bodo otroci igrali. Ti hipotezi smo oblikovali na podlagi nekaterih teoretskih izhodišč (npr. Russ in Christian, 2011; Singer in Singer, 1990; Vigotski, 1967/2004) in izsledkov empiričnih raziskav (npr. Berretta in Privette, 1990; Chu, Quek in Lin, 2011; Einsiedler, 1986; Howard-Jones, Taylor in Sutton, 2002; Nakamine, 1979; McGhee in sod., 1984; McLoyd, 1983; Robinson in Jackson, 1987; Suzuki, 1983; Treinies in sod., 1988). Petletniki zmorejo v igro vključiti bolj ali manj strukturiran, realističen in kompleksen igralni material, saj so njihove govorne sposobnosti in simbolno mišljenje dobro razvite (Eljkonin, 1984). Kljub temu smo pričakovali, da bo mera ustvarjalnosti bolj narasla pri tistih otrocih, ki so se igrali z manj strukturiranim, realističnim in kompleksnim materialom. Tovrsten material naj bi spodbujal produkcijo več domišljijskih tem, predmetnih zamenjav (Singer in Singer, 1990) in jih bolj motiviral $\mathrm{k}$ dejavnosti igre, na kar nakazujejo izsledki avtorjev nekaterih drugih navedenih empiričnih študij, ki so proučevali odnos med značilnostmi igralnega materiala in igro pri otrocih v zgodnjem otroštvu.

\section{Metoda}

\section{Udeleženci}

K sodelovanju v raziskavi smo povabili starše 93 otrok izbranega vrtca, ki so bili ob pričetku raziskave stari med pet in šest let. Poučeno soglasje za sodelovanje je podpisalo 66 staršev.

Zaradi osipa (bolezni, izpisi, počitnice) je v raziskavi sodelovalo 59 otrok, 25 je bilo dečkov in 34 deklic. Otroci so bili stari med 60 in 72 mesecev $(M=68$ mesecev oz. 5;8 let). 18,6 \% staršev otrok je imelo dokončan doktorat ali magisterij, 33,9 \% univerzitetno, 11,9 \% visokošolsko, 28,8 \% srednješolsko in $1,7 \%$ osnovnošolsko izobrazbo.

\section{Pripomočki}

Ustvarjalnost otrok smo želeli pridobiti s čim bolj objektivnim pripomočkom, zato smo se odločili za uporabo preizkusa sposobnosti in ne drugih metod, kot na primer opazovanja igre. Večina avtorjev sorodnih raziskav je sicer o ustvarjalnosti sklepala iz opazovanja igre otrok (Einsiedler, 1986; Marjanovič Umek in Lešnik Musek, 1998; McGhee in sod., 1984; McLoyd, 1983; Nakamine, 1979; Olszewski in Fuson, 1982; Oncu in Unluer, 2010; Pulaski, 1970; Robinson in Jackson, 1987; Suzuki, 1983), kjer so opazovali številčnost, raznolikost igralnih tem, razmerje med vsakdanjimi in domišljijskimi temami. V manjšem številu so avtorji uporabljali bolj objektivne pripomočke za merjenje ustvarjalnosti. Dansky (1980) je uporabil Preizkus alternativnih rab (Alternative Uses Task; Guilford, 1967b), Berretta in Privette (1990), Treinies in sod., (1988) Torranceove teste ustvarjalnega mišljenja TTCT (Torrance Tests of Creative Thinking; Torrance, 1972) in Yan (2005) Torranceov test ustvarjalnega mišljenja $v$ dejanju in gibanju TCAM (Torrance Thinking Creatively in Action and Movement; Torrance, 1981). $\mathrm{V}$ naši raziskavi smo mero ustvarjalnosti pridobili $\mathrm{s}$ Preizkusom ustvarjalnega mišljenja TCT-DP (Test for creative thinking - Drawing production; Jellen in Urban, 1986). Po navedbah avtorjev $\mathrm{z}$ omenjenim preizkusom ustvarjalno mišljenje ocenjujemo celostno in kulturno nepristransko. TCT-DP je hiter in enostaven za uporabo in vrednotenje, primeren za različne starostne skupine otrok (od petega leta naprej) ter omogoča prepoznavanje tako nadpovprečnih kot podpovprečnih udeležencev $\mathrm{v}$ meri ustvarjalnosti. Test se rešuje individualno ali v skupini in obsega eno testno polo. Udeleženci dobijo standardizirana navodila za reševanje testa. V časovno omejenem intervalu petnajst minut morajo dopolniti šest figur, ki že vsebujejo nekaj elementov (pika, polkrog, vijuga, prekinjena črta, dve pravokotnici, tri črte v obliki črke U), ki so znotraj okvirja oziroma brez okvirja. Figure, ki jih otrok nariše, se ocenjuje glede na 14 kriterijev: stalnost, dovršenost, uporaba novih elementov, zveznost med elementi, prisotnost tematike, preseganje mej glede na zunanji element, preseganje mej brez ozira na zunanji element, uporaba perspektive, humorja in čustvenih tem, nekonvencionalnost glede na uporabo materiala, abstraktnih elementov, simbolov ter hitrost. Končna ocena mere ustvarjalnosti je enovit seštevek posameznih 14 ocen. Avtorja testa sta navedla, da je koeficient notranje zanesljivosti $(\alpha)$ med 0,89 in 0,97 , kar je bilo ugotovljeno na vzorcu 112 sedmošolcev, starih med 12 in 13 let, s štirih različnih šol v Nemčiji (Jellen in Urban, 1985; v Urban, 2010). Gralewski in Karwowski (2012) sta poročala o nekoliko nižji, a še vedno dobri oceni notranje zanesljivosti, $\alpha=0,74$, ki je bila izračunana na vzorcu 589 poljskih srednješolcev, starih med 16 in 20 let. Koeficient notranje zanesljivosti, izračunan na našem vzorcu, je znašal 0,78. Slovenskih norm za Preizkus ustvarjalnega mišljenja TCT-DP nimamo, čeprav naj bi se preizkus lahko uporabljal za identifikacijo nadarjenih 
Tabela 1. Razvrstitev igralnega materiala po posameznih dimenzijah glede na njegove značilnosti

\begin{tabular}{|c|c|c|c|c|}
\hline \multirow{2}{*}{$\begin{array}{l}\text { Vrsta (skupina) } \\
\text { igralnega materiala }\end{array}$} & \multirow[b]{2}{*}{ Igrače } & \multicolumn{3}{|c|}{ lastnosti igralnega materiala } \\
\hline & & strukturiranost & realističnost & kompleksnost \\
\hline A & $\begin{array}{l}\text { mini kuhinja, set za igranje zdravnika, raziskovalni } \\
\text { set z mikroskopom }\end{array}$ & visoka & visoka & visoka \\
\hline B & $\begin{array}{l}\text { nestrukturirani polizdelki: tulci WC papirja, } \\
\text { paličice, risalni listi, žebljički, barvice in flomastri } \\
\text { ter rečni prodniki }\end{array}$ & nizka & nizka & nizka \\
\hline $\mathrm{C}$ & $\begin{array}{l}\text { modelirna masa, risalni papir, tempera barve za } \\
\text { slikanje in barvice za risanje }\end{array}$ & nizka & nizka & nizka \\
\hline $\mathrm{D}$ & lego kocke & nizka & nizka & visoka \\
\hline E & papirnate, ročne ali lutke na leseni žlici & visoka & visoka & nizka \\
\hline $\mathrm{F}$ & mobilne aplikacije za igro vlog & visoka & nizka & visoka \\
\hline
\end{tabular}

učencev (Žagar, Artač, Bezič, Nagy in Purgaj, 1999). V priročniku za uporabo Preizkusa ustvarjalnega mišljenja TCT-DP Urban (2010) navaja, da naj bi bile nemške norme primerne za uporabo tudi pri drugih populacijah, zlasti v evropskih oziroma zahodnih kulturah sorodnega socialno-ekonomskega ozadja.

Med igralnimi seansami smo uporabili šest vrst igralnega materiala (tabela 1). Vsak otrok se je igral le $\mathrm{z}$ eno skupino igralnega materiala. V skupini A so bile visoko strukturirane, visoko realistične in visoko kompleksne igrače, primerne za (samostojno) igro vlog: mini kuhinja, set za igranje zdravnika ter raziskovalni set $\mathrm{z}$ mikroskopom. Skupino B igrač so sestavljali nestrukturirani polizdelki: tulci WC papirja, paličice, risalni listi, žebljički, barvice in flomastri ter rečni prodniki, iz katerih so si otroci izdelovali svoje nizko realistične in nizko kompleksne igrače (vozila, lutke in improvizirana bivališča) in se z njimi tudi igrali. Nizko realistični in nizko kompleksni igralni material skupine $\mathrm{C}$ je vključeval modelirno maso, risalni papir, tempera barve za slikanje in barvice za risanje. Otrokom, ki so se igrali z igračami skupine $\mathrm{D}$, smo ponudili tri različne tematske sete lego kock: Lego Friends ${ }^{\odot}$, Lego City $^{\odot}$ in Lego $26 x^{\odot}$ (seti pohištva), ki so bili nizko strukturirani, nizko realistični, a visoko kompleksni, in s katerimi so lahko zgradili vozila, lutke in pohištvo. Poleg kock tematskih setov so jim bili na voljo tudi načrti za sestavljanje setov ter set generičnih gradnikov (Lego Basic ${ }^{\odot}$ ), katere so lahko prosto sestavljali. V skupini E so bile različne lutke in pripomočki: papirnate, ročne ali lutke na leseni žlici. V kolikor so želeli, so otroci lahko uporabljali miniaturen gledališki oder. Ponujen material je bil visoko strukturiran, visoko realističen in nizko kompleksen. $\mathrm{Na}$ mizi so bile postavljene sličice $\mathrm{z}$ motivi znanih pripovedi (pripoved o Treh prašičkih, Rdeči kapici, Ostržku). Skupina F je imela na voljo tri različne, visoko strukturirane in visoko kompleksne, a nizko realistične mobilne aplikacije za igro vlog na prenosnem telefonu, in sicer Toca Boca Helicopter Taxi $^{\odot}$, Toca Boca Hair Salon $\mathrm{Me}^{\odot}$ in Toca Boca Tailor ${ }^{\odot}$. Vse mobilne aplikacije, ki so jih otroci uporabljali na pametni napravi, so bile multimodalne in interaktivne, saj so vključevale vidne in slušne dražljaje, deloma so spodbujale gibanje po prostoru in se odzivale na otrokove reakcije. $Z$ aplikacijo Toca Boca Helicopter Taxi ${ }^{\circ}$ so otroci prek igre prevzemali vlogo voznika letečega taksija, ki jim je omogočala, da so prevažali »stranke« od ene do druge lokacije. S pomočjo tehnologije obogatene resničnosti, ki omogoča sestavljanje interaktivne podobe resničnega in virtualnega sveta, so prek fotoaparata na ekranu »videli skozi okno« navideznega helikopterja v realni prostor. Navidezni helikopter so lahko s svojim gibanjem skozi prostor krmilili, pri čemer je pametna naprava posnemala zvok letečega helikopterja. V aplikaciji Toca Boca Hair Salon $\mathrm{Me}^{\odot}$ so otroci uporabljali $\mathrm{v}$ pametno napravo integriran fotoaparat, s katero so lahko posneli poljubno fotografijo (najpogosteje sebe) in si v virtualnem frizerskem salonu urejali pričesko. Toca Boca Tailor ${ }^{\odot}$ jim je omogočala, da so animiranim junakom $v$ virtualni krojaški delavnici izdelali oblačilo. Obliko oblačil, modne dodatke (npr. očala, klobuk, lasulja) so izbirali iz vnaprej predvidenega nabora, pri teksturi oblačil pa so imeli več svobode, saj so jih ustvarjali s fotografijami, ki so jih posneli. Vse tri aplikacije so poleg vidnih informacij vsebovale tudi zvočne (npr. zvok letečega helikopterja, sušilca za lase, šivalnega stroja) dražljaje.

\section{Postopek}

Na podlagi seznama otrok, katerih starši so podpisali poučeno soglasje, smo za vsakega otroka določili, katero vrsto igralnega materiala bo uporabljal med desetimi igralnimi seansami. Otroke smo razvrstili tako, da se je z vsako vrsto igralnega materiala igralo enako število otrok in enako število deklic in dečkov. Zaradi osipa je bilo ob koncu raziskave $\mathrm{v}$ skupinah od devet do enajst otrok. Pred pričetkom prve igralne seanse so otroci posamično izpolnili TCT-DP, potem pa je v obdobju 11 tednov sledila serija desetih igralnih seans, po zadnji igralni seansi pa še ponovljeno merjenje s TCT-DP. Skozi vseh deset igralnih seans se je vsak otrok igral le $\mathrm{z}$ eno od šestih vrst igralnih materialov (A, B, C, D, E in F), ki so se med seboj razlikovale $\mathrm{v}$ dimenzijah značilnosti (strukturiranosti, realističnosti in kompleksnosti) oziroma po vrsti igralnega materiala (lutke, lego kocke, pametna 
Tabela 2. Opisne statistike rezultatov prvega in drugega merjenja ustvarjalnosti otrok glede na vrsto materiala, s katerim so se igrali otroci, ter razlike $v$ ustvarjalnosti med meritvama

\begin{tabular}{|c|c|c|c|c|c|c|c|c|}
\hline \multirow[b]{2}{*}{ Vrsta igralnega materiala } & \multirow[b]{2}{*}{$N$} & \multicolumn{2}{|c|}{ prvo merjenje } & \multicolumn{2}{|c|}{ drugo merjenje } & \multirow[b]{2}{*}{$F$} & \multirow[b]{2}{*}{$p$} & \multirow[b]{2}{*}{$\eta_{n}{ }^{2}$} \\
\hline & & $M$ & $S D$ & $M$ & $S D$ & & & \\
\hline A & 9 & 18,33 & 10,75 & 16,78 & 7,81 & 0,124 & 0,734 & 0,015 \\
\hline B & 10 & 17,60 & 8,91 & 21,70 & 6,62 & 2,828 & 0,127 & 0,239 \\
\hline $\mathrm{C}$ & 10 & 15,00 & 7,06 & 17,40 & 9,59 & 0,510 & 0,493 & 0,054 \\
\hline $\mathrm{D}$ & 10 & 16,30 & 8,43 & 14,10 & 6,81 & 1,592 & 0,239 & 0,150 \\
\hline $\mathrm{E}$ & 9 & 19,11 & 9,01 & 17,33 & 4,82 & 0,502 & 0,499 & 0,059 \\
\hline $\mathrm{F}$ & 11 & 14,45 & 3,62 & 17,00 & 7,66 & 0,904 & 0,364 & 0,083 \\
\hline
\end{tabular}

Opombe. A - igrače replike, B - improvizirane igrače, C - material za likovno izražanje, D - lego kocke, E - lutke, F - interaktivne igrače.

naprava, polizdelki, replike). Da se otroci ne bi naveličali igre $\mathrm{z}$ istim predmetom $\mathrm{v} 11$ tednih, smo jim izmenično dali na voljo eno od treh različnih igrač, a vedno enake vrste. Otroci so se igrali samostojno, in sicer v ločenem, a otroku znanem in domačem prostoru blizu igralnice $\mathrm{v}$ vrtcu. Testatorka je sedela $\mathrm{v}$ kotu prostora in $\mathrm{v}$ igro otrok ni posegala. $\mathrm{V}$ kolikor jo je otrok spontano vključil $\mathrm{V}$ igro, se je na pobudo odzvala tako, da je sledila njegovim navodilom, ni pa prevzemala iniciative za igro. Pred pričetkom vsake igralne seanse so otroci imeli na voljo eno minuto časa za prilagoditev in spoznavanje z igralnim materialom. Predviden časovni okvir igralne seanse je bil deset minut. Ker smo otrokom želeli zagotoviti sproščeno vzdušje oziroma spontan kontekst igre, smo jih po preteku desetih minut opozorili, da je čas za igro potekel. V kolikor so v dejavnosti vztrajali, smo jih čez dve minuti ponovno pozvali, naj zaključijo. Če so otroci izrecno izrazili željo (zelo redko), da nadaljujejo $\mathrm{z}$ dejavnostjo oziroma da potrebujejo več časa, da zaključijo, smo jim dovolili, a nobena igralna seansa ni trajala več kot 18 minut. Prav tako so lahko igralno seanso predčasno zaključili. Po vsaki seansi so si lahko izbrali žig z motivom živali ali risanih junakov.

\section{Rezultati}

Za analizo izbranega problema smo uporabili analizo variance (ANOVA) za mešan načrt, v katerem je bila mera ustvarjalnosti odvisna spremenljivka, testna in retestna situacija faktor znotraj oseb in vrsta igralnega materiala faktor med osebami. Sprva smo preverili ustreznost podatkov glede na predpostavke ANOVE za mešan načrt, in sicer da v podatkih ni osamelcev, da so vrednosti odvisne spremenljivke normalno porazdeljene $\mathrm{v}$ vseh skupinah udeležencev in da so variance $\mathrm{v}$ vseh skupinah udeležencev med seboj primerljive po velikosti (homogenost varianc). Homogenost varianc smo preverjali z Levenovim testom, s katerim smo ugotovili, da se variance mere ustvarjalnosti med skupinami pri prvem merjenju, $F(5,53)=2,0 ; p=0,09$, in pri drugem merjenju, $F(5,53)=0,70 ; p=0,63$, ne razlikujejo statistično značilno. Predpostavke o sferičnosti nismo preverjali, ker smo imeli le dve časovni točki merjenja. Pri pregledu prikazov zabojev z ročaji smo našli štiri univariatne osamelce, dva v skupini $A$, in enega $v$ skupini $C$ in $E$, vendar niso dosegali ekstremnih vrednosti. Osamelce smo ohranili v analizi, saj smo se prepričali, da ne gre za napako pri merjenju in tudi med postopkoma obdelave podatkov $\mathrm{z}$ ali brez osamelcev ni bilo bistvenih razlik. V razpravi bomo poskusili razložiti morebitne razloge za pojav osamelcev. Vrednosti mere ustvarjalnosti so bile normalno porazdeljene $\mathrm{v}$ vseh skupinah igrač pri prvem merjenju in pri skupinah B, C, D in F drugega merjenja, kar smo ocenili z Shapiro-Wilkovim testom. Porazdelitvi mere ustvarjalnosti pri drugem merjenju nista bili normalno porazdeljeni pri skupini A $(p=0,046)$ in $\mathrm{E}(p=0,034)$, ker sta bili nekoliko koničasti. Ker je bilo odstopanje od normalne porazdelitve zmerno, smo nadaljevali z uporabo analize variance. Preverjali smo veljavnost hipoteze o učinku časa, in sicer, da bo razlika v meri ustvarjalnosti med prvim in drugim merjenjem statistično pomembna. Testirali smo tudi hipotezo o učinku vrste igralnega materiala, pri kateri smo pričakovali, da se bo pokazala statistično pomembna razlika $\mathrm{v}$ meri ustvarjalnosti med različnimi vrstami igrač. Razlike v meri ustvarjalnosti pred in po igralnih seansah se niso izkazale za statistično pomembne, učinek časa pa je bil izredno majhen $F(1,53)$ $=0,238 ; p=0,627 ; \eta_{\mathrm{p}}{ }^{2}=0,004$. Učinek vrste igralnega materiala na mero ustvarjalnosti je bil zmerno velik in ni bil statistično pomemben, $F(5,53)=0,73 ; p=0,606$; $\eta_{\mathrm{p}}{ }^{2}=0,064$. Tudi učinek interakcije med časom merjenja in vrsto igrač je bil zmerno velik in prav tako ni bil statistično pomemben, $F(5,53)=0,870 ; p=0,508 ; \eta_{\mathrm{p}}{ }^{2}=0,076$.

Ker se je izkazalo, da velikost učinka interakcije ni bila zanemarljiva, smo z nizom enosmernih ANOV za ponovljene meritve preverili učinek časa merjenja znotraj posameznih skupin igrač. Zaradi majhnega števila udeležencev in posledično majhne statistične moči noben od učinkov časa merjenja ni bil statistično značilen (tabela 2). Kot je razvidno iz tabele 2, je v skupinah z igračami A, $\mathrm{D}$ in E prišlo do majhnega znižanja v povprečnih dosežkih na meri ustvarjalnosti, $\mathrm{v}$ preostalih skupinah pa do povišanja. Največje povišanje v izmerjeni ustvarjalnosti smo zabeležili v skupini B, tj. skupini otrok, ki se je igrala z improviziranimi igračami, ki so bile nizko strukturirane, nizko realistične in nizko kompleksne. 


\section{Razprava}

Pričakovali smo, da bo mera ustvarjalnosti otrok po desetih igralnih seansah narasla ter da bo mera ustvarjalnosti narasla različno glede na skupino igralnega materiala, s katerim se bodo otroci igrali. Hipotez nismo uspeli potrditi, saj glavni učinek časa (testna in retestna situacija), učinek vrste igralnega materiala in interakcija med njima niso bili statistično pomembni. Velikost učinka smo ocenili z delnim eta kvadratom. Učinek časa je bil zaradi različno velikih razlik in predvsem zaradi različne smeri razlik med meritvami po posameznih skupinah (v nekaterih skupinah je prišlo do porasta, $v$ nekaterih pa do znižanja dosežkov na ustvarjalnosti) praktično zanemarljiv, učinek vrste igralnega materiala in interakcije pa je bil zmeren (za smernice glede interpretacije velikosti učinka glej Cohen, 1988).

Kljub temu, da je bil učinek igralnega materiala statistično nepomemben, smo naknadno preverjali, kakšne so bile spremembe v meri ustvarjalnosti na ravni posamezne skupine igralnega materiala. Tudi tu ni bilo ugotovljenih statistično pomembnih razlik. A učinki znotraj nekaterih skupin so bili zmerni ali veliki in jih lahko interpretiramo v luči predhodnih empiričnih raziskav, ki se deloma skladajo s rezultati, ki smo jih opazili v naši raziskavi. Največjo pozitivno spremembo mere ustvarjalnosti smo zabeležili pri otrocih, ki so se igrali z nizko strukturiranim, nizko realističnim in nizko kompleksnim igralnim materialom (skupina igrač B). Velikost učinka spremembe ustvarjalnosti, ocenjena $\mathrm{Z}$ delnim eta kvadratom, je bila velika (Cohen, 1988), čeprav velja omeniti, da je lahko zaradi velikosti vzorca ta mera precenjena. A tudi nekateri drugi avtorji primerljivih raziskav poročajo o sorodnih učinkih igralnega materiala na ustvarjalnost otrok (Berretta in Privette, 1990; Einsiedler, 1986; McGhee in sod., 1984; McLoyd, 1983; Suzuki, 1983). Igralna dejavnost $\mathrm{z}$ nestrukturiranimi polizdelki, iz katerih so otroci izdelovali nizko realistične in nizko kompleksne igrače, jim je nudila največ svobode in izziva, saj so morali ob šibki podpori igralnega materiala iskati rešitve, kako uporabiti material in samostojno izdelati igrače, s katerimi so se lahko igrali. Za razliko od igrač replik (skupina A), ki zaradi informacij o funkciji spodbujajo posnemanje, igra $\mathrm{z}$ nestrukturiranimi polizdelki spodbuja več predmetnih transformacij, saj morajo otroci manjkajoče elemente nadomestiti $\mathrm{z}$ drugimi, pri čemer uporabljajo miselne pretvorbe, kar naj bi ugodno vplivalo na ustvarjalnost otrok (Einsiedler, 1986; McLoyd, 1983). Igralni material skupine $C$ je bil glede na fizične značilnosti in dimenzije (strukturiranost, realističnost, kompleksnost) soroden skupini B, vendar so otroci, ki so imeli na voljo tak material, dosegli le majhno spremembo v meri ustvarjalnosti. Predvidevamo, da je $\mathrm{k}$ temu prispevala pogosta izpostavljenost (doma in $\mathrm{v}$ igralnici) taki vrsti igralnega materiala oziroma manjše zanimanje za dejavnosti, ki so povezane $\mathrm{z}$ dobro poznanim materialom. Tudi pri otrocih, ki so se igrali z lego kockami (skupina D), razlika v meri ustvarjalnosti ni bila statistično pomembna, a je bila negativna. Velikost učinka, ki smo jo ocenili $\mathrm{z}$ delnim eta kvadratom, je bila velika glede na Cohenove smernice (1988). Padec ustvarjalnosti si razlagamo kot pomanjkanje možnosti izražanja otroka v igri, kar je bilo posredno opaziti tudi prek upada zanimanja za igro s tovrstnimi igračami. Otroci so zelo pogosto komentirali igralne sete, jih primerjali s seti, ki so jih že poznali oziroma imeli na voljo v igralnici ali doma in spraševali po določenih vrstah setov (npr. Lego Star Wars $^{\odot}$ ). Pogoste so bile tudi izjave o načinu sestavljanja (npr. da njim doma sete sestavijo starši, sami pa se z njimi le igrajo). Opazili smo, da so zlasti dečki igralne sete sestavili po načrtu, potem pa niso imeli več interesa, da bi se $\mathrm{z}$ njimi igrali. Igro s setom Lego Friends ${ }^{\odot}$ so dečki pogosto odklanjali z besedami, da je to »igrača za punce «. Glede na to, da je bila omenjena blagovna znamka igrač pogosto prisotna tudi izven igralnih seans (celo isti igralni seti) je možno, da je to prispevalo k manjšemu zanimanju za igro oziroma so otroci težje našli izvirne načine igranja s poznanimi predmeti. Slednje je sorodno ugotovitvam raziskave avtorjev Oncu in Unluer (2010), ki sta ugotovila, da se otroci $\mathrm{z}$ visoko strukturiranimi in realističnimi vsakdanjimi predmeti niso zmogli igrati na ustvarjalen način oziroma, da so bile predmetne transformacije manj verjetne, ko so otroci enkrat pripisali predmetu določeno funkcijo. Kljub temu, da so bili otrokom na voljo tudi generični gradniki, katere so lahko kombinirali skupaj z igralnimi seti ali pa uporabljali čisto samostojno, je možno, da je strukturiranost tematskih igralnih setov določila otrokovo dejavnost in so se otroci igrali na podoben način kot doma ali v igralnici. Glede na izjave otrok smo sklepali, da so bili otroci zelo dobro osveščeni o blagovni znamki Lego ${ }^{\odot}$ in bi lahko z njo povezovali tudi način igranja, kar je delno potrdila tudi M. Chaudhary (2013). Avtorica je ugotovila, da so otroci dobro poznali blagovne znamke proizvajalcev igrač in njihove izdelke ter da so bolj ali manj neposredno prek staršev vplivali na nakup igrač (Singh in Aggarwal, 2012; TIA, 2013). Otroci, ki so se igrali z multimedijsko igračo (skupina F), so na drugem merjenju pokazali zmerno visok porast $\mathrm{V}$ ustvarjalnosti, a le-ta ni bil statistično pomemben. Igralni material skupine $\mathrm{F}$ je bil visoko strukturiran in je otrokom omogočal igro vlog (voznik helikopterja, frizer in krojač). $\mathrm{V}$ tem pogledu je bil soroden igračam skupine A, vendar je mobilna aplikacija $\mathrm{v}$ virtualnem prostoru omogočala interaktivnost prek manipulacije lastnih fotografij in obogatene resničnosti. Kljub temu, da mobilne aplikacije razen predvidenih vlog niso omogočale drugih in tudi niso spodbujale generiranja drugih domišljijskih igralnih tem, so otroci izkazali zanimanje za tovrstno igro. Večje zanimanje za igro bi bilo lahko povezano tudi $\mathrm{z}$ oblikovanjem aplikacije. Virtualni prostor aplikacije ni bil spolno stereotipen (npr. barva, liki junakov). Za razliko od skupine igrač $\mathrm{A}$ in $\mathrm{D}$ dečki niso zavračali igrač z izjavami »to so igrače za punce«. K večjemu zanimanju otrok za igro s tovrstnim materialom je najbrž prispevalo dejstvo, da je bila dotična mobilna aplikacija slovenskem trgu neznana in se otroci izven igralnih seans $\mathrm{z}$ njo niso 
igrali. Zmerno velik upad v izmerjeni ustvarjalnosti, ki tudi ni bil statistično pomemben, se je pojavil pri otrocih, ki so se igrali z lutkami (skupina E). Glede na kvalitativno opazovanje igre predvidevamo, da je bila tovrstna dejavnost z lutkami zelo zahtevna, saj je moral otrok hkrati načrtovati pripoved zgodbe in se vživljati v vloge različnih likov. Nekateri dečki so popolnoma zavračali tovrstno obliko igre ali pa so pokazali manj interesa kot deklice. Slednje sovpada zizsledki raziskave Hartmanna in Brougèreja (2004), kjer so dečki za igro z lutkami pokazali manj zanimanja kot deklice, ki so se z lutkami rade igrale, vendar so prevladovale vsakdanje teme. Predvidevamo, da bi bila igra z lutkami manj zahtevna, če bi v igro vključili več otrok hkrati oziroma mentalno bolj kompetentnega partnerja, vrstnika ali odraslega. Takšne igralne situacije bi bile lahko bolj stimulativne, saj bi nudile otrokom več priložnosti za reševanje problemov. Skozi skupno igro z mentalno razvitejšim partnerjem otrok pridobiva nove informacije, zmogljivejši partner mu pomaga pri analizi, kategorizaciji predmetnega sveta, interpretaciji vzročnoposledičnih odnosov in ga zavestno ali nezavedno vodi $\mathrm{k}$ zahtevnejšim dejanjem, kar je neformalna oblika učenja $\mathrm{v}$ območju bližnjega razvoja, t.i. raven, ki presega otrokovo trenutno razvojno raven, predstavlja pa raven razvoja, ki jo bo otrok tudi samostojno zmogel $\mathrm{v}$ prihodnosti (Zupančič, 2006). Otroci bi skozi igro v območju bližnjega razvoja imeli priložnost razvijati nekatere sposobnosti (npr. metagovor, reševanje problemov), kar bi lahko imelo ugoden učinek na njihovo ustvarjalnost.

Da spremembe mere ustvarjalnosti niso bile statistično pomembne, je posledica predvsem majhne statistične moči, relativno velike razpršenosti mere ustvarjalnosti otrok znotraj posameznih skupin ter druge morebitne pomanjkljivosti raziskave, katere naslavljamo ob koncu razprave. Majhna statistična moč je vezana na majhno število udeležencev znotraj posameznih skupin. V naši raziskavi se je v posamezni skupini igralo od devet do enajst otrok znotraj posameznega pogoja. Za manjše skupine in veliko število pogojev smo se odločili, ker je bil naš namen raziskati, katere vrste oziroma značilnosti igralnega materiala bolj podpirajo ustvarjalno mišljenje otrok. Pri načrtovanju velikosti skupin in števila pogojev smo se opirali na zasnove predhodnih raziskav. Robinson in Jackson (1987) sta imela skupine do šest otrok in šest različnih pogojev, Einsiedler (1986) dvanajst otrok in dva pogoja. Do trideset otrok v posamezni skupini pa so imeli McGhee in sod., (1984), McLoyd (1983) in Pulaski (1970). Razpršenost ustvarjalnega mišljenja znotraj skupin (prvo merjenje) je bila relativno visoka, čeprav je bila povprečna vrednost in razpršenost mere ustvarjalnosti na ravni celotnega vzorca pri prvem merjenju $(N=59, M=16,7$ točke, $S D=8,0$ ) primerljiva $\mathrm{z}$ normami, pridobljenimi na nemškem vzorcu, $N=214, M=16,5$ točke, $S D=8,6$ (Urban, 2010). Povprečne vrednosti kot tudi razpršenost mere ustvarjalnosti znotraj šestih skupin naše raziskave močneje odstopajo od omenjenih norm. Iz tabele 1 je razvidno, da je najnižja povprečna vrednost $\mathrm{v}$ meri ustvarjalnosti 14,5 , najvišja pa 19,1 , najnižja ocenjena razpršenost je znašala 3,6, najvišja pa 10,8. Iz teh vrednosti sklepamo, da je bila napaka vzorčenja visoka, kar je lahko prispevalo $\mathrm{k}$ temu, da razlike $\mathrm{v}$ meri ustvarjalnosti med prvim in drugim merjenjem niso dovolj natančno izmerjene. Poleg relativno visoke razpršenosti znotraj skupin smo v rezultatih imeli tudi štiri osamelce, ki sicer niso dosegali ekstremnih vrednosti. Ko smo se prepričali, da pri oceni ustvarjalnosti ni šlo za mersko napako, smo se odločili, da jih ne izvzamemo iz nadaljnje analize. Tri vrednosti od štirih osamelcev so bile dosežene na prvem merjenju ustvarjalnosti in sodijo v skupino petih najvišjih rezultatov. Glede na nemške norme (Urban, 2010) sodi teh pet vrednosti v percentilni rang od 91 do 100. Pri otrocih, ki so v prvem merjenju dosegli tako visoke rezultate, je bilo značilno, da smo ob drugem merjenju ustvarjalnosti zabeležili višjo negativno razliko. Ker je ustvarjalnost relativno stabilen konstrukt (Arnold in sod., 2011), hitre in drastične spremembe niso verjetne. Predvidevamo, da so ta nihanja ustvarjalnosti povezana $z$ drugimi dejavniki, kot na primer z (izkazanim) upadom otrokovega zanimanja za igro ali pa z mankom primernih možnosti izražanja otrokove ustvarjalnosti. Opazili smo, da so otroci, ki so dosegali na prvem merjenju najvišje rezultate, pogosteje predhodno zaključevali igralne seanse oziroma spraševali po dodatnih igračah. Možno je, da so se hitreje naveličali igre $\mathrm{z}$ istimi oziroma enako vrsto igrač kot tudi reševanja enakega testa, saj naj bi bili ustvarjalni posamezniki bolj odprti do novih izkušenj in težili $\mathrm{k}$ iskanju novih dražljajev (npr. McCrae, 1987; Schaeffer, 1976). K nedoseganju pričakovanih rezultatov so lahko prispevali tudi drugi dejavniki, kot na primer pomanjkljivosti pri zasnovi raziskave in uporaba preizkusa ustvarjalnosti, ki bi bil lahko manj občutljiv za merjenje ustvarjalnosti $\mathrm{v}$ zgodnjem otroštvu. Raziskavo smo izvajali v otrokovem naravnem okolju (vrtcu), zato smo se morali prilagajati številnim okoliščinam v vrtcu (npr. odsotnost otrok zaradi bolezni, interesne dejavnosti otrok). Mnogih dejavnikov nismo mogli nadzirati (npr. katere igrače otroci uporabljajo doma in v igralnici) ali zagotavljati enakih pogojev (npr. vnaprej določen in reden urnik igralnih seans). Pogosta izpostavljenost določenim vrstam igralnega materiala bi lahko imela na otrokovo ustvarjalnost pozitivni učinek (npr. zaradi seštevalnega učinka) ali pa negativnega (npr. zaradi manjšega zanimanja za dobro poznan igralni material). Nadaljnje, zaradi stabilne narave konstrukta ustvarjalnosti, je bila morda doba 11 tednov prekratka, da bi lahko opazili pomembne razlike pri ustvarjalnosti, izmerjene s preizkusom ustvarjalnega mišljenja. Sicer menimo, da je bila pogostost in trajanje igralnih seans $\mathrm{V}$ naši raziskavi primerno odmerjena, saj so druge primerljive raziskave potekale $\mathrm{v}$ krajšem časovnem intervalu kot naša ali pa so imele manjše število ponovitev (Einsiedler, 1986; Nakamine, 1979; Olszewski in Fuson, 1982; Oncu in Unluer, 2010; Pulaski, 1970; Treinies in sod., 1988). Pripomoček za merjenje ustvarjalnosti je po navedbi avtorjev primeren za uporabo že pri otrocih od petega leta starosti (Urban, 2010). TCT-DP se lahko uporablja tudi pri štiriletnikih, vendar Urban opozarja, da so pri tej starosti 
povprečni in podpovprečni rezultati manj zanesljivi kot nadpovprečni oziroma rezultati pri starejših testirancih. O nižji zanesljivosti merjenja ustvarjalnosti v zgodnjem otroštvu smo posredno sklepali na podlagi primerjav povprečnih vrednosti mer ustvarjalnosti nemških norm, kjer Urban navaja, da je starost imela pomemben učinek na povprečno mero ustvarjalnosti, vendar tega učinka ni bilo pri najmlajših testirancih (med četrtim in šestim letom starosti). Štiriletniki so dosegli najnižjo povprečno mero ustvarjalnosti, petletniki pa višjo kot šestletniki. Predvidevamo, da bi bila lahko zanesljivost merjenja ustvarjalnosti s TCT-DP na spodnji priporočeni starostni meji nižja zaradi narave ocenjevanja ustvarjalnosti, ki sloni na likovnemu izražanju ustvarjalnih idej. Stagnacija oziroma padec izmerjene ustvarjalnosti bi bila lahko vezana tudi na razvojno stopnjo sposobnosti risanja oziroma tehnične omejitve otroka pri risanju. Risba petletnika je na predshematski stopnji (Marjanovič Umek, 2009), kar otroku lahko predstavlja tehnično omejitev oziroma mu otežuje dosledno izražanje, strukturiranje in elaboriranje ustvarjalne ideje. Otrok nariše podobo krajine kot shemo črt, kar opazovalcu in ocenjevalcu testa ne nudi dovolj informacij, da bi lahko sklepal o otrokovi nameri in izdelek oceni nižje od izdelka zmožnejšega testiranca, ki lahko zaradi razvitejših sposobnosti risanja bolj elaborira svojo izvirno idejo. Izražanje otrok, starih med pet in šest let, naj bi bilo pretežno spontano, egocentrično in hedonistično (Dudek, 1974), saj otroci na predkonvencionalni stopnji manj inhibirajo nekonvencionalne ideje in se manj dobesedno izražajo (Runco, 2006). Vendar razvojne stopnje razvoja niso togo vezane na starost, zato bi bilo možno, da otroci v tej starosti že prehajajo na konvencionalno stopnjo in (nedosledno) izkazujejo namero po bolj dobesednem, realističnem izražanju, vendar zaradi tehničnih omejitev, ki so vezane na predshematsko stopnjo risanja, svojih namer ne zmorejo primerno elaborirati in jih dosledno izraziti. Predpostavljamo, da je k statistični nepomembnosti razlik v meri ustvarjalnosti prispevalo delovanje več naštetih dejavnikov hkrati. Kot najbolj kritična bi izpostavili predvsem relativno majhno število otrok ter veliko razpršenost mere ustvarjalnega mišljenja znotraj skupin.

\section{Zaključek}

Kljub temu, da razlike $\mathrm{v}$ meri ustvarjalnosti niso bile statistično pomembne, bi izpostavili, da smo zabeležili največji porast $\mathrm{v}$ meri ustvarjalnosti $\mathrm{v}$ skupini nizko strukturiranih, nizko realističnih in nizko kompleksnih igrač (skupina B), kar je sorodno izsledkom nekaterih drugih raziskav (Berretta in Privette, 1990; Einsiedler, 1986; McGhee in sod., 1984; McLoyd, 1983; Suzuki, 1983). Na podlagi izsledkov teh raziskav avtorji predpostavljajo, da nizko strukturiran, nizko realističen in nizko kompleksen material otrokom nudi največ priložnosti za predmetne transformacije kot tudi izzive, pri katerih otroci rešujejo probleme. $\mathrm{V}$ naši raziskavi nismo primerjali učinkov vključevanja odraslih oziroma razvitejših vrstnikov $\mathrm{v}$ otrokovo igro in samostojne igre na ustvarjalnost otrok. Predvidevamo, da igralni material nima tako velike vloge, da bi lahko zgolj s svojimi fizičnimi in funkcionalnimi lastnostmi nudil otroku podporo ali dodatno stimulacijo pri razvoju otroka. Zmogljivejši igralni partner lahko v večji meri izkoristi danosti igralnega materiala kot tudi svoje zmožnosti in razumevanje igre, kar bi lahko prispevalo k razvoju otrokove ustvarjalnosti. Pri nadaljnjih študijah bi poleg merjenja ustvarjalnosti s preizkusi predlagali tudi analizo razvojne stopnje igre, kjer bi lahko pridobili bolj poglobljen vpogled v otrokovo ustvarjalnost znotraj igralnega konteksta, vključevanje večjega vzorca otrok in zmanjšanje števila različnih vrst igralnega materiala.

\section{Literatura}

Arnold, K. D., Subotnik, R. F. in Ross, M. (2011). Longitudinal studies. V M. A. Runco in S. R. Pritzker (ur.), Encyclopedia of creativity (str. 62-67). San Diego, CA, ZDA: Academic Press.

Berretta, S. in Privette, G. (1990). Influence of play on creative thinking. Perceptual and Motor Skills, 71, 659-666.

Chaudhary, M. (2013). Role of children in the family buying (povzetek doktorske disertacije). Pridobljeno s http:// www.jiit.ac.in/uploads/Post\%20Viva\%20Synopsis_ Monica.pdf.

Chu, S. L., Quek, F. in Lin, X. (2011). Studying medium effects on children's creative processes. V A. K. Goel, F. Harrell, B. Magerko, Y. Nagai in J. Prophet (ur.), Proceedings of the 8th ACM Conference on creativity (str. 3-12). ACM conference on Creativity and cognition; Atlanta, GA, 3.-6. november, 2011. New York: ACM.

Cohen, J. (1988). Statistical power analysis for the behavioral sciences. Hillsdale, NJ, ZDA: Lawrence Erlbaum Associates.

Csikszentmihalyi, M. (1990). Flow: The psychology of optimal experience. New York, NY, ZDA: Harper and Row.

Dacey, J. (2011). Historical conceptions of creativity. V M. A. Runco in S. R. Pritzker (ur.), Encyclopedia of creativity (str. 608-616). San Diego, CA, ZDA: Academic Press.

Dansky, J. L. (1980). Make-believe: A mediator of the relationship between play and associative fluency. Child Development, 51, 576-579.

Dudek, S. Z. (1974). Creativity in young children attitude or ability? The Journal of Creative Behavior, 8, 282-292.

Einsiedler, W. (1986). Fantasy play of preschoolers as a function of toy structures. V R. van der Kooij in J. Hellendoorn (ur.), Play, play therapy, play research (str. 259-278). Lisse, Nizozemska: Swets Zeitlinger. 
Eljkonin, D. B. (1984). Psihologija dječje igre [Psychology of child's play]. Beograd, Srbija: Zavod za udžbenike i nastavna sredstva.

Gralewski, J. in Karwowski, M. (2012). Creativity and school grades: A case from Poland. Thinking Skills and Creativity, 7, 198-208.

Guilford, J. P. (1967a). Creativity: Yesterday, today and tomorrow. The Journal of Creative Behavior, 1, $3-14$.

Guilford, J. P. (1967b). The nature of human intelligence. New York, NY, ZDA: McGraw-Hill.

Hartmann, W. in Brougère, G. (2004). Toy culture in preschool education and children's toy preferences. V J. H. Goldstein, D. Buckingham in G. Brougere (ur.), Toys, games, and media (str. 37-53). Mahwah, NJ, ZDA: Lawrence Erlbaum Associates.

Howard-Jones, P., Taylor, J. in Sutton, L. (2002). The effect of play on the creativity of young children during subsequent activity. Early Child Development and Care, 172, 323-328.

Jellen, H. G. in Urban, K. K. (1986). The TCT-DP (Test for creative thinking - Drawing production): An instrument that can be applied to most age and ability groups. Creative Child and Adult Quarterly, 11, $138-155$.

Kaufman, J. C. in Sternberg, R. J. (2010). Preface. V J. C. Kaufman in R. J. Sternberg (ur.), The Cambridge handbook of creativity (str. xiii-xvi). Cambridge, Združeno kraljestvo: Cambridge University Press.

Lewin, K. (1931). Environmental forces in child behavior and development. V C. Murchison (ur.), A handbook of child psychology (str. 94-127). Worcester, MA, ZDA: Clark University Press.

Lillard, A. S., Lerner, M. D., Hopkins, E. J., Dore, R. A, Smith, E. D. in Palmquist, C. M. (2013). The impact of pretend play on children's development: A review of the evidence. Psychological Bulletin, 139, 1-34.

Marjanovič, L. (1981). Otroške igračke [Child's toys]. V L. Marjanovič (ur.), Igra in igrače [Play and toys] (str. 17-24). Ljubljana, Slovenija: Zveza prijateljev mladine.

Marjanovič Umek, L. (2009). Razvoj otroške risbe [The development of the child's drawing]. V L. Marjanovič Umek in M. Zupančič (ur.), Razvojna psihologija [Developmental psychology] (str. 349-406). Ljubljana, Slovenija: Rokus Klett.

Marjanovič Umek, L. in Fekonja Peklaj, U. (2008). Sodoben vrtec: Možnosti za otrokov razvoj in zgodnje učenje [Contemporary kindergarten: Possibilities for the child's development and early learning]. Ljubljana, Slovenija: Znanstvenoraziskovalni inštitut Filozofske fakultete.

Marjanovič Umek, L. in Lešnik Musek, P. (1998). Kako igrače in igralni materiali določajo naravo domisljijske igre [How toys and other playing materials determine the nature of the imaginary play]. Sodobna Pedagogika, 49, 154-166.
Marjanovič Umek, L. in Zupančič, M. (2009). Socialni in moralni razvoj $\mathrm{v}$ srednjem in poznem otroštvu [Social and moral development in the middle and late childhood]. V L. Marjanovič Umek in M. Zupančič (ur.), Razvojna psihologija [Developmental psychology] (str. 451-467). Ljubljana, Slovenija: Rokus Klett.

McCrae, R. R. (1987). Creativity, divergent thinking, and openness to experience. Journal of Personality and Social Psychology, 52, 1258-1265.

McGhee, P. E., Ethridge, L. in Benz, N. A. (1984). Effect of level of toy structure on preschool children's pretend play. The Journal of Genetic Psychology, 144, 209-217.

McLoyd, V. C. (1983). The effects of the structure of play objects on the pretend play of low-income preschool children. Child Development, 54, 626-635.

Nakamine, A. (1979). Yooji no schoochooasobi ni oyobosu ganguto-kuesei no kooka [Effects of toy type on children's imaginative play]. Japanese Journal of Educational Psychology, 27, 62-66.

Olszewski, P. in Fuson, K. C. (1982). Verbally expressed fantasy play of preschoolers as a function of toy structure. Developmental Psychology, 18, 57-61.

Oncu, E. C. in Unluer, E. (2010). Preschool children's using of play materials creatively. Procedia - Social and Behavioral Sciences, 2, 4457-4461.

Piaget, J. (1962). Play, dreams and imitation in childhood. New York, NY, ZDA: Norton.

Pulaski, M. A. S. (1970). Play as a function of toy structure and fantasy predisposition. Child Development, 41, 531-537.

Robinson, C. C. in Jackson, R. (1987). The effects of varying structure within a prototypical play object on the solitary pretend play of preschool children. Journal of Applied Developmental Psychology, 8, 209-220.

Runco, M. A. (2006). Development of children's creativity. V B. Spodek in O. N. Saracho (ur.), Handbook of research on the education of young children (str. 121-134). Mahwah, NJ, ZDA: Lawrence Erlbaum Associates.

Runco, M. A. (2007). Creativity: Theories and themes: Research, development, and practice. San Diego, CA, ZDA: Academic Press.

Runco, M. A. (2011). Developmental trends in creative abilities and potentials. V M. A. Runco in S. R. Pritzker (ur.), Encyclopedia of creativity (str. 376378). San Diego, CA, ZDA: Academic Press.

Russ, S. W. (2001). Primary-process thinking and creativity: Affect and cognition. Creativity Research Journal, 13, 27-35.

Russ, S. W. (2004). Play in child development and psychotherapy. Mahwah, NJ, ZDA: Lawrence Erlbaum Associates.

Russ, S. W. (2011). Emotion/Affect. V M. A. Runco in S. R. Pritzker (ur.), Encyclopedia of creativity (str. 659669). San Diego, CA, ZDA: Academic Press. 
Russ, S. W. in Christian, K. M. (2011). Play. V M. A. Runco in S. R. Pritzker (ur.), Encyclopedia of creativity (str. 238-243). San Diego, CA, ZDA: Academic Press.

Russ, S. W. in Fiorelli, J. A. (2010). Developmental approaches to creativity. V J. C. Kaufman in R. J. Sternberg (ur.), The Cambridge handbook of creativity (str. 233-249). Cambridge, Združeno kraljestvo: Cambridge University Press.

Schaeffer, C. E. (1976). Intercorrelations among measures of creativity, openness to experience and sensation seeking in a college sample. College Student Journal, 10, 332-339.

Singer, D. G. in Singer, J. L. (1990). The house of make-believe: Children's play and the developing imagination. Cambridge, MA, ZDA: Harvard University Press.

Singh, R. in Aggarwal, V. K. (2012). Role of children in family purchase decision making - a comparative study among children of different age groups in Punjab and Chandigarh, India. International Journal of Research in Management, Economics and Commerce, 2, 161-176.

Smith, G. J. W. in Carlsson, I. (1983). Creativity in early and middle school years. International Journal of Behavioral Development, 6, 167-195.

Sternberg, R. J. (1988). A three-facet model of creativity. V R. J. Sternberg (ur.), The nature of creativity: Contemporary psychological perspectives (str. 125147). Cambridge, Združeno kraljestvo: Cambridge University Press.

Suler, J. R. (1980). Primary process thinking and creativity. Psychological Bulletin, 88, 144-165.

Suzuki, K. D. (1983). Effects of creative and idealized toys on children's play. Referat predstavljen leta 1983 na simpoziju Biennial meeting of The society for research in child development, Detroit, MI, ZDA, 21.-24. april 1983. Pridobljeno s http://eric.ed.gov/?id=ED229137.

Torrance, E. P. (1968). A longitudinal examination of the fourth grade slump in creativity. Gifted Child Quarterly, 12, 195-199.

Torrance, E. P. (1972). Torrance Tests of Creative Thinking: Directions manual and scoring guide. Figural test booklet A. Bensenville, IL, ZDA: Scholastic Testing Service.

Torrance, E. P. (1981). Thinking creatively in action and movement. Bensenville, IL, ZDA: Scholastic Testing Service.

TIA Toy Industry Association. (2013). Toy and game family decision making study (bela knjiga). Pridobljeno s http://www.toyassociation.org/App_Themes/tia/ pdfs/resources/reports/FamilyDecisionMakingWhitePaper.pdf.

Treinies, G., Einsiedler, W. in Bosch, E. (1988). Der Einfluß der Spielzeugkomplexität auf das Phantasiespiel 3 bis 6 jähriger Kinder. Empirische Pädagogik, 2, 33-43.

Urban, K. K. (2010). Test for creative thinking - manual - TCT - DP. Frankfurt, Nemčija: Pearson Assessment and Information.
Vygotsky, L. (1967/2004). Imagination and creativity in childhood. Journal of Russian and East European Psychology, 42, 7-97.

Wachs, T. D. (1985). Toys of the physical environment: Constraints and nature of relationship to development aspect. Topics in Early Childhood Special Education, $5,31-46$.

Weisberg, R. W. (1988). Problem solving and creativity. V R. J. Sternberg (ur.), The nature of creativity: Contemporary psychological perspectives (str. 148176). Cambridge, Združeno kraljestvo: Cambridge University Press.

Yan, L. (2005). An investigation of the relationship between the open-endedness of activities and the creativity of young children (doktorska disertacija). Pridobljeno s http://scholarworks.uno.edu/cgi/ viewcontent.cgi? article $=1308 \&$ context $=t d$.

Zupančič, M. (2006). Vloga odraslega v otrokovi igri [The role of an adult in child's play]. V L. Marjanovič Umek in M. Zupančič (ur.), Psihologija otros ke igre: od rojstva do vstopa $v$ solo [The psychology of child's play: From birth to school entry] (str. 107-123). Ljubljana, Slovenija: Znanstvenoraziskovalni inštitut Filozofske fakultete.

Žagar, D., Artač, J., Bezič, T., Nagy. M. in Purgaj, S. (1999). Koncept. Odkrivanje in delo z nadarjenimi učenci $v$ devetletni osnovni šoli [Concept. Recognizing of and working with the gifted students in nine-year primary school]. Ljubljana, Slovenija: Zavod RS za šolstvo. 